\title{
FEATURE Research topics to scale up cover crop use: Reflections from innovative lowa farmers
}

\author{
Andrea D. Basche and Gabrielle E. Roesch-McNally
}

C over crops as a conservation practice continue to receive attention from farmers, researchers, media, and policy makers, given their ability to effectively reduce water pollution and improve soil quality. Recent estimates of cover crop use across the midwestern Corn Belt, as well as the United States, demonstrate large acreage increases over the last number of years. The annual Sustainable Agriculture Research and Education-Conservation Technology Information Center (SARECTIC) survey found that nationally cover crop acreage doubled from 2011 to 2016, based on farmers self-reporting cover crop planting (CTIC 2016). However, the total cover crop acreage based on 2012 Census of Agriculture data only represents 3.2\% of harvested cropland nationally and just $2.3 \%$ of the total cropland in the US Corn Belt (USDA NASS 2014a, 2014b).

Cover crops can be a difficult proposition for many farmers in highly productive agricultural regions where priority is given to maximizing crop production and economic returns year to year. The practice is particularly challenging in the upper midwestern portion of the Corn Belt because the climate limits the time to seed and effectively grow another crop following the fall harvests of corn (Zea mays L.) and soybean (Glycine max [L.] Merr.). Farmers frequently report challenges with amount of time to get a cover crop established on a larger number of farmed acres, as well as cash crop production risks (Arbuckle and Roesch-McNally 2015; CTIC 2013, 2014, 2015). In an effort to understand cover crop use in the region, researchers have previously found that there are various predictors of cover crop use in farming

Andrea Basche is a Kendall Science Fellow with the Food and Environment Program at the Union of Concerned Scientists in Washington, DC. Gabrielle Roesch-McNally is a research fellow at the Northwest Regional Climate Hub, part of the US Forest Service Pacific Northwest Research Station, in Corvallis, Oregon. Both are former graduate students at lowa State University, Ames, lowa. operations, including producers who have favorable perceptions of cover crop benefits as well as those with higher levels of crop diversity and livestock in their operation (Singer et al. 2007; IRFLP 2012). While the prior research on cover crop adoption is very informative in outlining why cover crops are utilized by some farmers and not others, it does not necessarily examine how farmers are making cover crops work in the dominant cornbased cropping systems of the Midwest.

Understanding how cover crops are implemented requires focusing not only on individual farmer decision making but also on broader structural challenges. This includes constraints such as economic pressures for high productivity and time limitations of corn-soybean crop rotations. It has been suggested that because there are many structural obstacles to cover crop use, there may not be wide adoption unless a more diversified agricultural system is adopted throughout the region, which would help facilitate the markets and infrastructure required for greater ease and affordability of cover crops (RoeschMcNally et al. 2017). In a review of conservation practice adoption literature, Carlisle (2016) also concluded that the broader systemic context under which producers operate cannot be ignored. Blesh and Wolf (2014) further found that the trend toward a less diverse agricultural landscape inhibited adoption of more agroecological farming systems.

Given the complexity of barriers that exist in instituting cover crops, Carlson and Stockwell (2013) outlined priorities for cover crop research based on the questions and concerns commonly expressed by farmers within intensive corn-soybean production systems. In this article, we build on those topics through the examination of data collected during focus group discussions with Iowa farmers. Their shared experiences underscore the need for more research that facilitates a productive feedback-loop with researchers and end users of information. Ultimately, the more that farmer perspectives are incorporated into cover crop research, the more that research can assist in making the practice relevant for different regions and on individual farms.

\section{FOCUS GROUPS WITH CONSERVATION- MINDED FARMERS}

To further explore how producers have integrated cover crops in their operations, we facilitated four focus groups across the state of Iowa in July of 2014 (RoeschMcNally et al. 2017). Focus groups are a qualitative research method that queries individuals on a particular topic in a group setting, cost effectively providing a forum for analysis of social interactions and cultural norms (Warr 2005). We recruited potential participants from existing farmer networks, including the state USDA Natural Resources Conservation Service (NRCS), Practical Farmers of Iowa, and Iowa State University Extension. Our goal was to recruit participants that generally reflected the predominant corn-soybean producers in the state and who also had an interest in cover crops. In total we had 29 farmer participants; $69 \%$ had solely managed a corn-soybean crop rotation and $31 \%$ had a third or fourth crop or pasture in their operation. The median size of operations for our participants was 120 ha $(290 \mathrm{ac})$, slightly below the average size of farms in Iowa, estimated to be 140 ha (346 ac) (USDA NASS 2014a). Our farmer participants were unique for the state, as all but three had previously planted a cover crop on their operations.

During the focus groups, one member of the research team presented information to the participants, and a second member of the team facilitated the discussion. The presentation included a compilation of long-term research efforts related to cereal rye (Secale cereale L.) cover crops in Iowa. This was done in an effort to bring all participants to the same understanding of current research findings, which is common in focus group design (Onwueghuzie et al.2009). The presentation included information on yield, water quality, soil erosion, economics, and agronomic modeling (table 1). 
Participants were asked to respond to the information presented, which elicited a conversation on how farmers have overcome economic and agronomic challenges to achieve success with cover crops in cornsoybean cropping systems (Roesch-McNally et al.2017). During the conversations, a series of questions arose, providing valuable insights from this group of conservation-minded producers. These questions are important in progressing the research agenda by providing a more nuanced, in-depth understanding of how farmers might better integrate cover crops into their operations.

There were several topics that arose in all four of the focus group discussions, and each will be discussed separately in the following sections, using direct quotes from participants to illustrate key themes. The three main topics raised by farmers during the discussions, related to further cover crop research, addressed below are (1) revaluing soil resources at the farm and landscape scale; (2) cover crop species options beyond cereal rye; and (3) a desire for more systems- level cover crop research (research that incorporates multiple elements of management changes), in order to best incorporate cover crop and cash crop interactions.

\section{REVALUING SOIL RESOURCES AT THE FARM AND LANDSCAPE SCALE}

To describe the potential benefits and costs of cover crops for participants, we shared information on direct seeding and termination costs, potential cost share options, as well as small credits for water pollution and erosion prevention (table 1). It was

\section{Table 1}

Information presented during farmer focus groups and sample questions asked of farmers regarding these topics.

\begin{tabular}{|c|c|}
\hline Topic & Main results presented \\
\hline $\begin{array}{l}\text { Experimental research site } \\
\text { long-term results from Boone } \\
\text { County, lowa (results based on } \\
\text { Kaspar et al. [2012]) }\end{array}$ & $\begin{array}{l}\text { - Average } 314 \mathrm{~kg} \mathrm{ha}^{-1}\left(5 \mathrm{bu} \mathrm{ac}^{-1}\right) \text { decline in corn and } 67 \mathrm{~kg} \mathrm{ha}^{-1} \\
\text { (1 bu ac}-1) \text { decline in soybeans with the use of a cereal rye cover } \\
\text { crop over six seasons of corn and six seasons of soybean } \\
\text { - Overseeding cereal rye into corn or soybean by last week } \\
\text { of September results in average biomass of } \sim 1,700 \mathrm{~kg} \mathrm{ha-1} \\
\left(1,500 \mathrm{lb} \mathrm{ac}^{-1}\right) \\
\text { - } 55 \% \text { less nitrate }\left(\mathrm{NO}_{3}\right) \text { load found in water collected from } \\
\text { tile drains with cover crops, average of } 10 \mathrm{~kg} \text { nitrogen }(\mathrm{N}) \mathrm{y}^{-1} \\
\left(23 \mathrm{lb} \mathrm{N} \mathrm{yr}{ }^{-1}\right)\end{array}$ \\
\hline $\begin{array}{l}\text { Four to five years of data from } \\
\text { replicated trials on farmer fields } \\
\text { across lowa, between } 2008 \\
\text { and } 2013 \text { (results based on } \\
\text { Practical Farmers of lowa and } \\
\text { lowa Learning Farms farmer }\end{array}$ & $\begin{array}{l}\text { - Average of } 67 \mathrm{~kg} \mathrm{ha}^{-1}\left(1 \mathrm{bu} \mathrm{ac}^{-1}\right) \text { increase in soybeans and } \\
314 \mathrm{~kg} \mathrm{ha}^{-1}\left(5 \mathrm{bu} \mathrm{ac}^{-1}\right) \text { decline in corn with a cereal rye cover } \\
\text { crop across on-farm trials } \\
\text { - Data skewed by one notable year of herbicide failure, } \\
\text { indicating that management is very important for avoiding } \\
\text { yield declines }\end{array}$ \\
\hline
\end{tabular}

Example questions asked to farmers

-What is your initial response to the information on

the experimental research plots and field-level trials?

-When thinking about using cover crops on your farm, how concerned are you about the potential impacts

to your cash crop yields?

- Of the factors explored here-yield, biomass accumulation, and $\mathrm{NO}_{3}$ retention-which one matters the most to you when thinking about using cover crops? Are there other factors that would be more interesting to you?

cooperator data [PFI and ILF

2014, 2015])

Model simulations and economic analysis (modeling results based on Basche et al. [2016], erosion prevention costs based on Duffy [2013], and water quality improvement based on work of Kaspar et al. [2012] assuming 2014 fertilizer costs)
- Early planting scenario (aerial seeding in early September) predicted double the amount of cereal rye growth, compared to postharvest planting scenario, with minimal yield impacts to corn and soybean

- A cover crop was predicted to increase in $\mathrm{NO}_{3}$ retention by $16 \%$ to $35 \%$ (early vs. later planting)

- A cover crop was predicted to reduce erosion by $18 \%$ to $35 \%$ (early vs. later planting)

- Cover crop costs and benefits vary from year to year; estimates of net costs ranged from US $\$ 103$ to US\$170 ha-1 (US\$42 to US\$69 $\mathrm{ac}^{-1}$ )

- The 2014 Natural Resources Conservation Service Environmental Quality Incentives Program cost share value was US\$96 ha-1 (US\$39 $\left.\mathrm{ac}^{-1}\right)$

-Erosion savings varied by region, assuming an on-farm value of US\$2.30 $\mathrm{t}^{-1}$ (US\$2.10 $\left.\mathrm{tn}^{-1}\right)$ of soil and a public value of US\$5.45 t-1 (US\$4.95 tn-1)
- How did these planting date scenarios influence the way you think about cover crop management? -What other kinds of scenarios would you want to see in terms of management practices?

-When you evaluate the benefits of cover crops, how important is erosion prevention to you?

- In what ways was the economic information we presented realistic?

-What information concerning cover crop benefits or challenges was lacking from this presentation? 
obvious that the presentation of economic data was incongruent with participants' experience of the numerous benefits that cover crops accrued on their farms; namely that many participants felt that the benefits of cover crops on improving soil health and reducing erosion was undervalued. They described soil as "priceless," and several expressed that there is a larger cost to society, particularly due to erosion from corn and soybean fields, which traditional cost-benefit analyses, including the one that was presented to them during the focus group, tend to ignore. One participant asked the question, "Why do our counties have to go around and clean out road ditches? Where'd that come from? ...I mean, there ... there's costs to doing nothing." This farmer was describing the fact that many counties dredge drainage ditches, which has a cost to taxpayers, and to society more broadly. However, it is often not incorporated into the costs of production for farms that contribute to erosion.

Further on this topic, another participant expressed the idea that soil stewardship should be reflected in land values.

I'd like to see a numeric value for soil health that can be something that is just like our corn suitability rating or our nitrogen, phosphorus [values]. I mean, we all have numbers in our head, but the one thing we don't know is what our soil health was and, if we knew that, and we could start comparing it, maybe even land would be sold with, if you had a higher soil ... health rating, or if you were renting land or renting it out, that would be huge, if there was a [soil health] scale.

Another participant specifically mentioned that organic matter accumulation in soil was a way to economically evaluate the benefit of cover crop use and to offset negative environmental impacts of bare soil.

We're farming some of that erodible stuff that has been eroded. I mean, I started renting a farm four years ago that the organic matters didn't even quite average $1 \%$. It had been abused and abused and abused for years and years and years. And that's where we're really throwing this rye grass [cover crop] at it to try to bring it around. It's coming, it's coming. It's no overnight fix but ... I mean, a lot of this stuff we're assuming that doing what we did is no cost. But there is a cost over time ... to stay doing what we've been doing.

Some participants recognized that the long-term research site data presented during the focus groups was from a generally flat field without the challenges of topography or low soil quality that many farmers have to deal with, and one even described how research on soil protection should be conducted in these more challenging environments.

It looked to me like the field that you're doing your research on is some pretty good dirt. Try some on some hills. ... That's where the biggest benefit's going to be. I think there's a benefit everywhere. But from the environmental standpoint, conservation, retaining nutrients, increasing the farmer's yield and stuff like that, you're going to get the bigger benefit. I mean, it's fun to do research on flat, black dirt. It's even fun to build houses on that stuff. But you need to ... It's [farms are] not all that way.

\section{COVER CROP SPECIES OPTIONS BEYOND CEREAL RYE}

During the focus groups, the research presentation aimed to share only longterm cover crop impacts, and as a result the focus was on cereal rye. This is the cover crop species with the most research in Iowa given that cereal rye has a high cold tolerance and fast germination rate, making it well suited for the state's winter growing season. Many farmers asked questions about what other options were suitable and potentially viable for Iowa. This resulted in information sharing from those who had prior experience with more diverse cover crop species. In particular, one farmer expressed a desire for noncereal species to be grown ahead of corn.
You would expect when a pure cereal rye in front of corn, it's going to be hard not to get a yield drag a little bit and, if you get some broad leafs, especially legumes, you could reverse that and actually get a yield bump. Livestock would be more wonderful too. And then also how poor your soil is, the more benefits you're going to see [from] the cover crops.

Other participants recognized that other regions are experimenting with cover crop mixes and that this could offer a great benefit in Iowa as well, if there were more information to answer basic management questions.

If I can figure out a way that I can actually build. ... this soil up is more my driving force so, you know, everything I'm seeing and reading and everything agrees with the statement about looking for a more diverse [cover crop] mix. By the same token, I got to learn to crawl before I can learn to walk and definitely before I can learn to get in the sprints so I think I'm going to. ... I'm going to go back to straight rye this year.

During conversation about other cover crop species, it was further suggested by another participant that a viable solution might be to test shorter season cultivars of corn and soybeans to allow for a shorter growing season for a cash crop thus enabling a larger window for cover crop establishment in the fall

I have seen some data and, I don't remember where, in one of the farm magazines on, and I don't know if it was Illinois or if that was Pennsylvania but ... where they did some yield trials looking at earlier varieties of corn and beans. And it was working, you know. They were coming out better than their longer varieties so, which is kind of the opposite of what we've all been [doing].

\section{THE NEED FOR MORE SYSTEMS-LEVEL COVER CROP RESEARCH}

When farmers were posed with questions about what additional information or scenarios they might like to see studied by researchers, they often shared answers reflecting the complexity of fac- 
tors that they manage on their farming operation. It is important to note that traditional agronomy field plot experiments are designed for statistical inference and to detect the impact of one single factor, such as altered fertilizer rates or tillage practices. Participants in multiple focus groups described a desire for a more complex "systems" approach to research, as one farmer expressed:

It's a system. You've got to get everything right and, you know, some of the researchers at some of the universities, they don't change anything when they do a cover crop study. Everything's the same and the cover crop's going to lose every time.

Often in response to questions about what additional information they might like to see, participants expressed questions related to nutrient management of corn following a cover crop. Another exchange revealed this desire for more multifactor research designs including nitrogen $(\mathrm{N})$ management, as well as the participants' perceptions of the shortcomings of traditional agronomic experiments.

Participant 1: It seemed like from Iowa State with your research, bring, if you can, bring the people together, let the nitrogen guys, put them together, the ag engineering guys and the agronomy people, put them all together. Like we're talking about the system approach. It's not just ...

Participant 2: Don't do the same thing you always did where you had cover crops just to see what it does.

Participant 1: Put everything together and do everything right and then see what [works] ...

Participants expressing a desire for multifactor experiments that are more realistic enough for them could reflect that they are constantly juggling multiple management aspects in their own operations. Farmers are not working to detect statistical differences, which gives them more flexibility to experiment in ways that researchers are often unable to do. Other participants reiterated the idea that in order to ensure a cover crop outperforms a no-cover trial, multiple management aspects require shifting.

You got to do everything right. It's not just all that simple ... that we'll just plant rye and we'll do things that way we already did, always did. I think you need to do things right to make it work well, but I think you can get just as good of yields and you can get all the advantage of soil savings and we think we're improving the soil's tilth and the organic matter level. So there's a lot of advantages, but probably have to make some [management] changes.

These questions often led participants to exchange valuable information with each other (Roesch-McNally et al. 2017) regarding the multiple management aspects that they alter when including a cover crop on their farms.

\section{FARMER PRIORITIES CAN HELP SHAPE FUTURE RESEARCH QUESTIONS}

Farmer participants in our study expressed several useful suggestions that can help shape future cover crop research. From our synthesis of these farmer conversations, we recommend three areas valuable for future cover crop research:

1.The economic benefits of soil be further studied and properly evaluated given that cover crops, and other conservation practices, can offset some of the societal costs of agricultural production.

2. Where possible, agricultural researchers modify their agronomic systems to accommodate cover crop growth and response of the cash crops: for example, executing systems-level experiments that incorporate multiple management elements, such as fertilizer management, herbicide, equipment needs, and tillage.

3. More region-specific information on diverse cover crops options.

The goal in sharing reflections from this innovative group of farmers is to help to facilitate a participatory feedback loop between farmers and various stakeholders involved in agricultural research. Without question, there are already numerous organizations working with farmers on cover crop research; however, if scaling up of best management conservation practices is to be achieved, researchers should continue to seek advice from their end users and find innovative ways to incorporate their input into future research endeavors. This is particularly important in creating more resilient agroecosystems that focus on soil and water conservation.

\section{ACKNOWLEDGEMENTS}

We would like to thank the 29 focus group participants for sharing their experiences and making this work possible. We would also like to thank our additional collaborators on this project: J. Arbuckle, associate professor, Iowa State University, Ames, Iowa; Fernando Miguez, associate professor, Iowa State University, Ames, Iowa; John Tyndall, associate professor, Iowa State University, Ames, Iowa; Troy Bowman, assistant professor, Alabama A\&M University, Normal, Alabama; and Rebecca Clay, Peace Corps fellow. This research was funded by the Leopold Center for Sustainable Agriculture (Grant Award \# E2014-20). This research was also a part of a regional collaborative project supported by the USDA National Institute of Food and Agriculture (NIFA), Award No. 2011-68002-30190, Cropping Systems Coordinated Agricultural Project: Climate Change, Mitigation, and Adaptation in Corn-based Cropping Systems.

\section{REFERENCES}

Arbuckle, J.G., and G.E. Roesch-McNally. 2015. Cover crop adoption in Iowa: The role of perceived practice characteristics. Journal of Soil and Water Conservation 70(6):418-429, doi:10.2489/ jswc.70.6.418.

Basche, A.D., S.A. Archontoulis, T.C. Kaspar, D.B. Jaynes, T.B. Parkin, and F.E. Miguez. 2016. Simulating long-term impacts of cover crops and climate change on crop production and environmental outcomes in the Midwestern United States. Agriculture, Ecosystems and the Environment 218:95-106.

Blesh, J., and S.A. Wolf. 2014. Transitions to agroecological farming systems in the Mississippi River Basin: Toward an integrated socioecological analysis. Agriculture and Human Values 31(4):621-635.

Carlisle, L. 2016. Factors influencing farmer adoption of soil health practices in the United States: A narrative review. Agroecology and Sustainable Food Systems 40(6):583-613.

Carlson, S., and R. Stockwell. 2013. Research priorities for advancing adoption of cover crops 
in agriculture-intensive regions. Journal of Agriculture, Food Systems, and Community Development 3(4):125-29.

CTIC (Conservation Technology Information Center). 2013. Report of the 2013-2014 Cover Crop Survey. West Lafayette, IN: Conservation Technology Information Center and Sustainable Agriculture Research and Education.

CTIC. 2014. 2012-2013 Cover Crop Survey. West Lafayette, IN: Conservation Technology Information Center and Sustainable Agriculture Research and Education.

CTIC. 2015. 2014-2015 Annual Report Cover Crop Survey. West Lafayette, IN: Conservation Technology Information Center and Sustainable Agriculture Research and Education.

CTIC. 2016. 2015-2016 Annual Report Cover Crop Survey. West Lafayette, IN: Conservation Technology Information Center and Sustainable Agriculture Research and Education.

Duffy, M. 2013. Cost of Eroded Soil. Iowa State University Extension and Iowa Learning Farms publication, January 2013. https://www.extension.iastate.edu/ilf/sites/www.extension.iastate. edu/les/ilf/Cost_of_Eroded_Soil.pdf.

IRFLP (Iowa Rural Farm and Life Poll). 2012. Summary Report. https://store.extension.iastate. edu/Product/Iowa-Farm-and-Rural-Life-Poll2012-Summary-Report.

Kaspar, T.C., D.B. Jaynes, T.B. Parkin, T.B. Moorman, and J.W. Singer. 2012. Effectiveness of oat and rye cover crops in reducing nitrate losses in drainage water. Agricultural Water Management 110:25-33.

Onwuegbuzie, A.J., W.B. Dickinson, N.L. Leech, and A.G. Zoran. 2009. A qualitative framework for collecting and analyzing data in focus group research. International Journal of Qualitative Methods 8(3):1-21.

PFI (Practical Farmers of Iowa) and ILF (Iowa Learning Farms). 2015. Winter cereal rye cover crop impact on cash crop yield: Year 6. Ames, IA: Practical Farmers of Iowa and Iowa Learning Farms. http://practicalfarmers.org/farmer-knowledge/ research-reports/2015/winter-cereal-rye-covercrop-effect-on-cash-crop-yield-year-6/.

PFI and ILF. 2014.Winter cereal rye cover crop impact on cash crop yield: Year 5. Ames, IA: Practical Farmers of Iowa and Iowa Learning Farms. http://practicalfarmers.org/farmer-knowledge/ research-reports/2014/winter-cereal-rye-covercrop-effect-cash-crop-yield/.

Roesch-McNally, G.E., A.D. Basche, J.G. Arbuckle, J.C. Tyndall, F.E. Miguez, T. Bowman, and R.M. Clay. 2017. The trouble with cover crops:
Farmers' experiences with overcoming barriers to adoption. Renewable Agriculture and Food Systems. doi:10.1017/S1742170517000096.

Singer, J.W., S.M. Nusser, and C.J.Alf. 2007.Are cover crops being used in the US Corn Belt? Journal of Soil and Water Conservation 62(5):353-58.

USDA NASS (USDA National Agriculture Statistics Service). 2014a. Census of Agriculture: Census by State. Wasthington, DC: USDA National Agricultural Statistics Service. http://
Www.agcensus.usda.gov/Publications/2012/ Full_Report/Census_by_State/.

USDA NASS. 2014b. Census of Agriculture: US National Level Data. Wasthington, DC: USDA National Agricultural Statistics Service. https:// www.agcensus.usda.gov/Publications/2012/ Full_Report/Volume_1,_Chapter_1_US/.

Warr, D. J. 2005. “It was fun... but we don't usually talk about these things": Analyzing Sociable Interaction in Focus Groups. Qualitative Inquiry 11(2):200-225. 